\title{
Modeling and Simulation of a Novel Switched Reluctance Motor Drive System with Power Factor Improvement
}

\author{
G. Venkatesan, R. Arumugam, M. Vasudevan, S. Paramasivam and S. Vijayan \\ Department of Electrical and Electronics Engineering, College of Engineering \\ Guindy,Anna University, Chennai-25, Tamil Nadu ,India
}

\begin{abstract}
This study presents a novel Switched Reluctance Motor (SRM) drive system with power factor improvement. Recently, many of the converters with variable speed drives have no input power factor correction circuits. This results in harmonic pollution of the utility supply, which should be avoided. The effect of power factor variation in terms of harmonic content is also analyzed in this study. The different operations like single pulse, soft chopping and hard chopping modes are done with and without a power factor controller. This study describes the buck - boost converter topology with above said methods for SRM drive. The boost converter is used to improve the input sinusoidal current and the buck converter is used to regulate the dc source voltage. The proposed topologies were simulated using MATLAB / Simulink software package and the results were obtained. The computer simulation results support the proposed methods.
\end{abstract}

Key words: Modeling, simulation, power factor improvement

\section{INTRODUCTION}

Now a days, Switched Reluctance Motor (SRM) drives have been used for aerospace systems, marine propulsion systems, linear drives, mining drives, hand held tools and home utilities applications. The main reason for using SRM is, it is a simple, low cost, robust structure, high ratio of torque to rotor volume, reliability, controllability and high efficiency. The SRM is also suitable for variable speed as well as servo type applications ${ }^{[1,2]}$. For fractional horsepower applications, high volume of SRM drive systems has been recommended. Although structure of SRM is simple, it draws a pulsating ac line current, resulting in low power factor and high harmonic line current. The switching of the phase winding is done by power converter and the input current becomes to distortion. This will reduces the quality of the input current waveform. With increasing demand for better power quality, this approach is no longer suitable for high performance SRM drive. The best way to obtain a high power factor is the use of a power factor correction circuit (PFC) with SRM drive.

SRM drives, on the other hand, are normally supplied from a stable dc link voltage. If a simple rectifier and a large dc-link capacitance produce the dclink voltage, the associated harmonics can exceed the limits given in the existing norms at relatively low powers. Some sort of PFC is, therefore, needed to meet these norms. Quite often, this makes the SRM solution too expensive to be considered further. Though, SRM drive has these drawbacks, it is chosen for high performance applications based on its improved features like efficiency, dynamics and full fourquadrant operation ${ }^{[3]}$. In the viewpoint of energy saving to improve the power factor and to maintain the input current sinusoidally is very important ${ }^{[4-7]}$. To improve the power factor, researchers have introduced the following power factor correction methods, which have been employed recently:

* Diode Bridge Rectifier With Stable DC-Link Voltage $^{[3]}$

* Diode Rectifier With Pulsating DC-Link Voltage ${ }^{[3]}$

* Diode Bridge Rectifier Plus Step-Up Converter ${ }^{[3]}$

* Buck- Boost converter ${ }^{[8]}$

The selection of these methods depends on the application of the drive, specifically, on the power, the speed, the performance wanted and the possible system costs.

The first method is only suitable for low-power applications. Even though, the system has many advantages including higher efficiency in all working points, high reliability, high starting torques and fourquadrant operation $^{[3]}$, is not suitable for high power applications. The second method is employed only for medium-power range applications, it could be worthwhile investigating whether a reduction in the dclink capacitance could assure that the limits in the norms are obeyed. However, most often this will prove to low system performance. If the system is driven at higher speeds mostly, increasing phase and/or rotor pole number could help to meet the requirements up to $2 \mathrm{kHz}$. In the upper power range upto $3.5 \mathrm{~kW}$,

Coresponding Author: G. Venkatesan, Department of Electrical and Electronics Engineering, College of Engineering, Guindy, Anna University, Chennai-25, Tamil Nadu, India 
third method is used, a PFC will have to be used for variable-speed operation. In order to reduce costs, it should be tried to integrate the design within the SR system. The additional volume and costs arise from the inductor needed in the PFC. This should, therefore, be operated in continuous mode and be manufactured together with the lamination material of the motor ${ }^{[7]}$. It should be operated at the highest possible frequency. The fourth method describes buck -boost converter topology with rotor position sensor. The boost converter used to improve the input sinusoidal current and the buck converter used to regulate the dc source voltage responding to the motor speed variation. The converter operation is done only in single pulse current $\operatorname{mode}^{[3]}$.

From the literature survey, it is observed that none of the papers discussed buck boost converter topology for power factor correction circuit in SRM drive system. Hence, this study mainly focused in a buckboost converter topology for PFC, which is designed, for single pulse current, soft chopping and hard chopping modes.

\section{SR MOTOR OPERATION}

As shown in Fig. 1, SR motor has simple structure with salient poles on both the stator and rotor. It has no windings or magnets on the rotor. The concentrated windings on the stator are wound around each tooth and diametrically opposite stator windings are connected in series or parallel. A 3-phase SR motor with a 6/4 structure is considered in this study. The operation of the SR motor is based on the minimum reluctance principle, that is, the rotor will always try to align its poles with the position that provides minimum reluctance for the magnetic circuit. To make the rotor rotate in one direction, the stator phase windings are energized following a determined sequence. The stator conduction sequence must be synchronized to the rotor position by means of a position sensor. Since the inductances of the stator windings depend on the reluctance of the magnetic circuit, they vary as a function of the rotor position. The variation of the phase inductances is shown in Fig. 2. If saturation is neglected, it can be shown that the motor torque is given $^{[1,9]}$ :

$T=\frac{1}{2} i^{2} \frac{d L}{d \theta}$

Where, $i$ is the instantaneous stator current and $d L / d \theta$ is the variation of phase inductance with rotor position. The developed torque is proportional to the square of the current so that it is independent of the current direction $^{[1,2]}$. This means that the converter is only required to produce unidirectional currents. Positive torque is produced by injecting constant currents into the phases during the rising portions of their inductance profiles and negative torque by

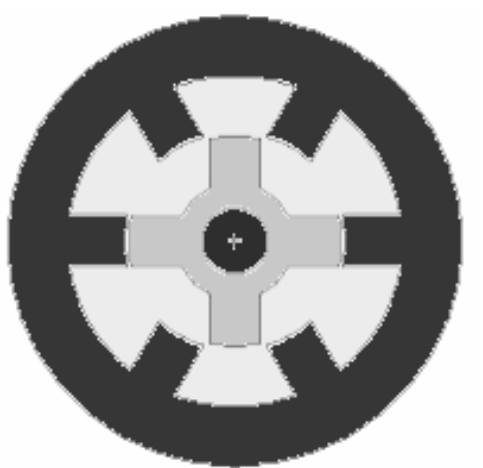

Fig. 1: Cross section of 6/4 SRM

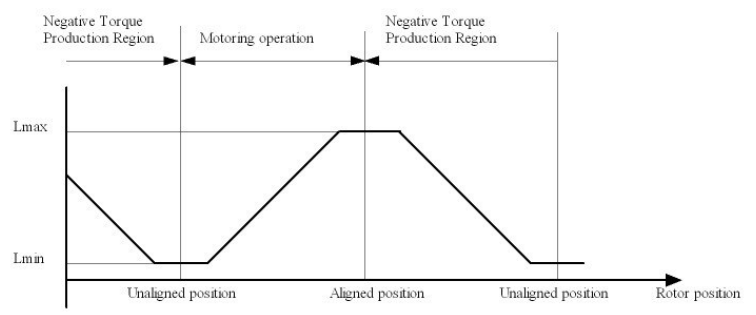

Fig. 2: Ideal Inductance variation

exciting the phases when their inductances are decreasing. As a result, motoring or braking operation can be obtained simply by changing the switching angle of the current in the stator windings. The rotation direction can be changed by inverting the switching sequence of the converter switches.

\section{SR MOTOR CONVERTER OPERATION}

In SRM converter, two switches and two diodes are used for per phase windings of the SRM as shown in Fig. 3. The switching action of this circuit is as follows:

* When both the switches T1 and T2 are ON, then the winding is in energizing mode.

* When both the switches T1 and T2 are OFF, then the winding is in de-energizing mode.

* When any one of the switches is ON and another switch is OFF, then the winding is in current regulation mode.

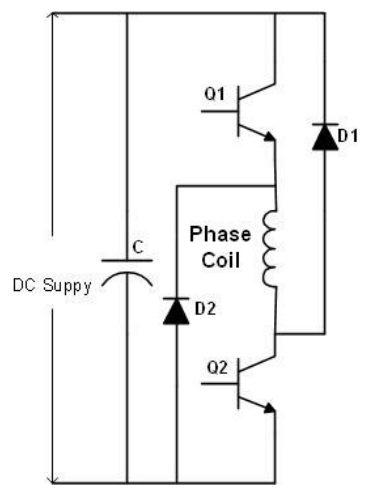

Fig. 3: SRM per phase converter 


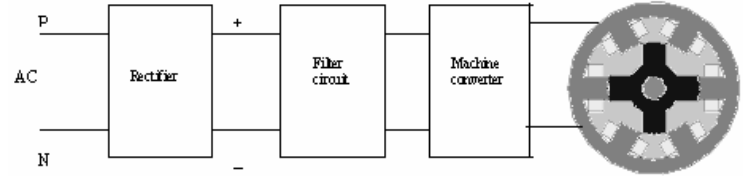

Fig. 4: Schematic diagram of SRM Without power factor controller

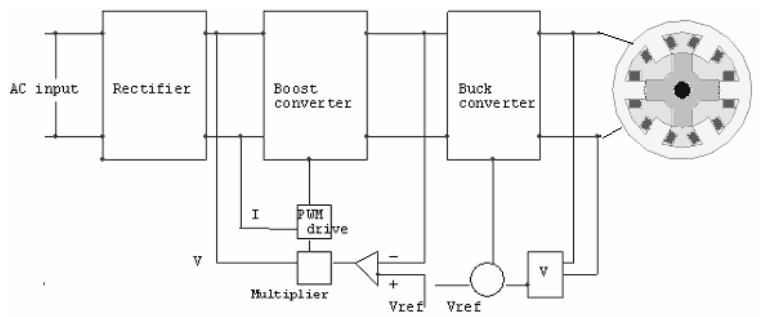

Fig. 5: Schematic diagram of SRM With power factor controller

\section{SCHEMATIC DIAGRAM OF SRM}

Figure 4 illustrates the conventional drive with rectifier and filter circuit. The filter circuit reduces the voltage ripple. However, it draws a pulsating ac line current, resulting in low power factor and high harmonic line current at the time of switching of the phase winding of SRM by machine converter. Figure 5 shows the proposed single-stage PFC with SRM drive. In this drive, buck-boost converter is introduced to minimize the distortion of line current at the switching the windings of SRM. This is accomplished by sensing the output current and voltage of rectifier.

\section{OPERATING MODES OF CLASSICAL SRM DRIVE}

Single pulse operation: In this method the switches T1 and T2 shown in Fig. 3 are continuously turned ON during the dwell angle for the particular phase. During that period no signal will be given to other phases. This mode is applicable only for high speed operation of SRM. The different types of operating modes like normal, boost, advanced dwell angle and braking modes are possible. In this mode no controlling algorithms will be implemented for speed and torque. The voltage and current waveforms for this particular operation is shown in the Fig. 6.

Soft chopping operation: In this method, the PWM signal to the switch $\mathrm{T} 1$ was made $\mathrm{ON}$ and OFF and the switch T2 continuously ON during the dwell angle for the particular phase. This method is applicable only for low speed operation. SRM operates at soft chopping mostly in normal mode operation. In this mode the torque and current ripple are less. The voltage and current waveforms for this particular operation is shown in the Fig. 7.

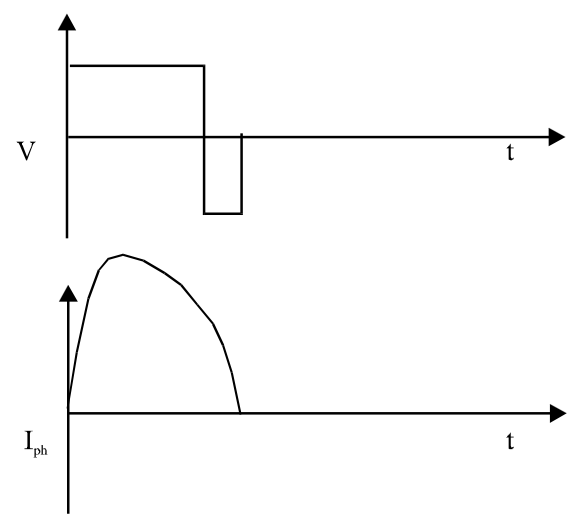

Fig.6: Voltage and current waveforms for single pulse mode


Fig. 7: Voltage and current waveforms for soft chopping mode
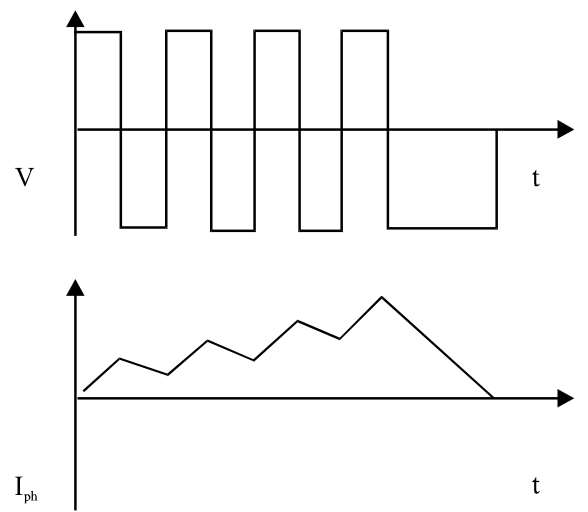

Fig. 8: Voltage and current waveforms for Hard chopping mode

Hard chopping operation: In this method, switches T1 and $\mathrm{T} 2$ are turned $\mathrm{ON}$ and OFF simultaneously. SRM drive at this kind of chopping mostly works in normal mode operation. Generally, this method is preferred for Low speed operation. The controlling of speed and torque are possible in this method. The torque ripple and current ripple are more in this method. The voltage and current waveforms for this particular operation is shown in the Fig. 8. 
In classical SRM drive, the different motor converters like classic bridge converters, c-dump converters and mid-point converters were used to drive the motor. Other than these converters, to improve the power factor, buck- boost converter with single pulse operation used ${ }^{[8]}$.

\section{OPERATING MODES OF PROPOSED SRM DRIVE}

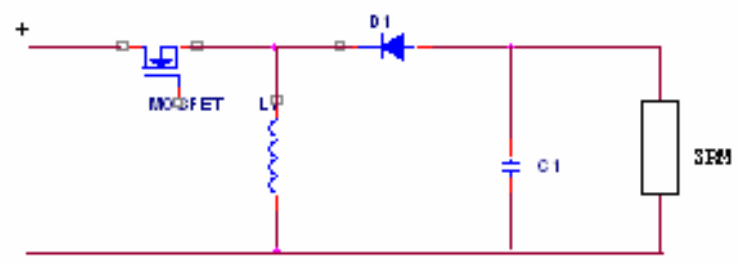

Fig. 9: Buck-boost regulator

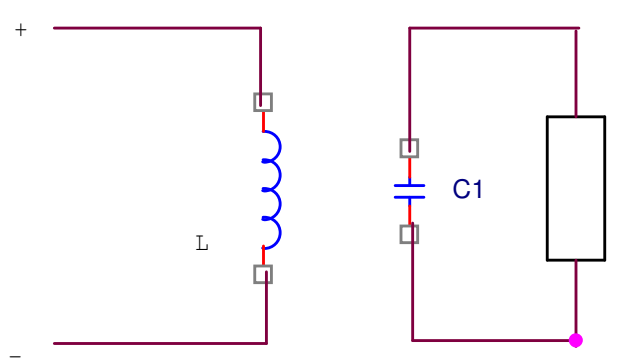

Fig. 10: Mode 1

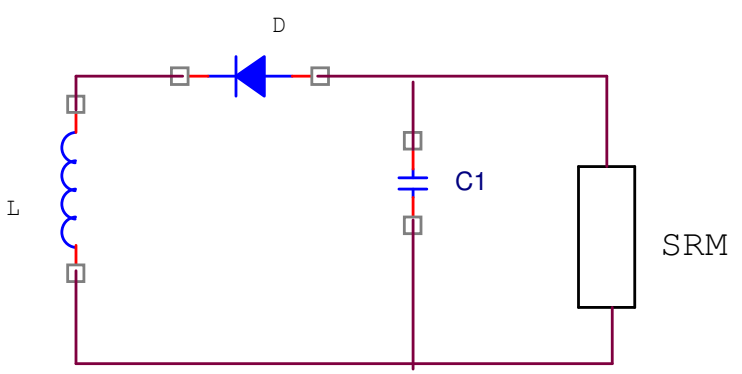

Fig. 11: Mode 2

Buck Boost converter topology: The buck-boost regulator as shown in Fig. 10 provides an output voltage that may be less than or greater than the input voltage. During the mode 1 as shown in Fig. 11 the switch is turned on and the diode D is reverse biased. The input current, which rises, flows through inductor $\mathrm{L}$ and the switch. During the mode 2 in Fig. 12, the switch is off and the current, which was flowing through inductor L, would flow through L, C,D and the load. The energy stored in inductor L would be transferred to the load and the inductor current would fall until the switch on again in the next cycle.

\section{SIMULATION PROCEDURE AND RESULTS}

A $1.2 \mathrm{~kW}, 160 \mathrm{~V}, 16 \mathrm{~A}$ SRM was considered for the simulation. The proposed scheme is simulated in
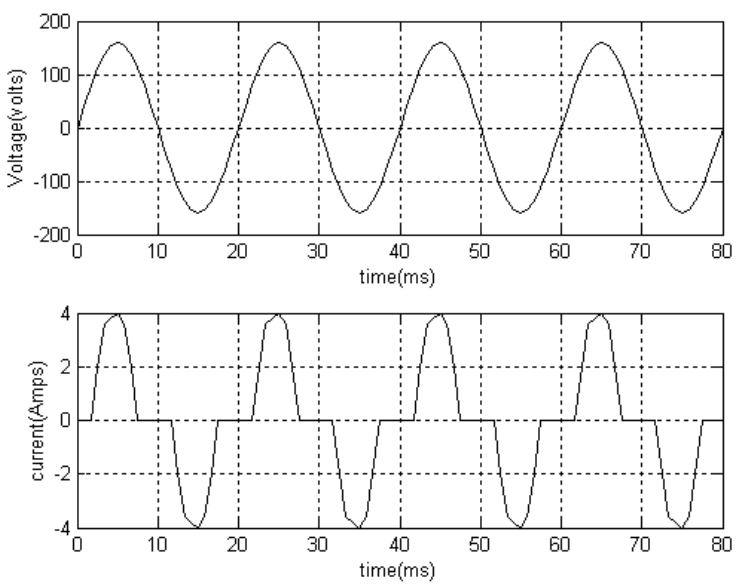

Fig. 12: Input voltage and current waveforms without power factor correction circuit
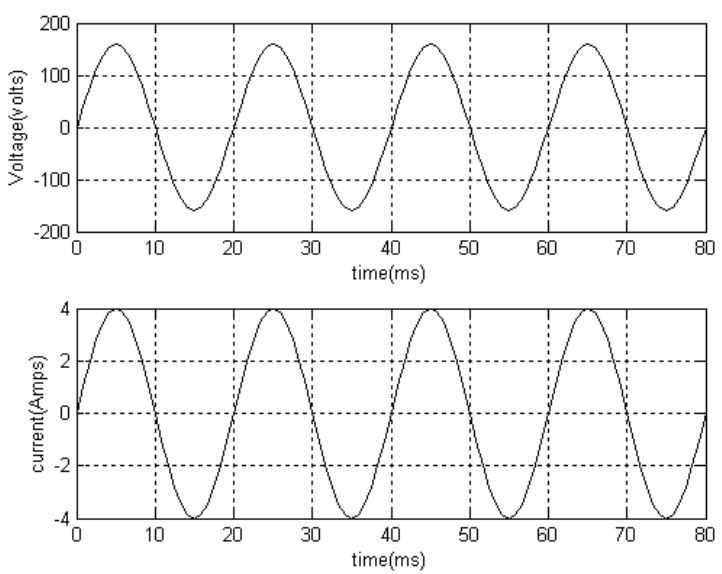

Fig. 13: Input voltage and current waveforms with power factor correction circuit at Single pulse operation

MATLAB / SIMULINK software platform. Figure 12 shows the input voltage and current waveforms without power factor correction circuit. This figure shows four cycles of voltage and current, which is for one revolution of SRM. Current waveform is looking distorted and which would be smoothened by introducing power factor correction circuit. By introducing PFC, current becomes smooth in single pulse operation as shown in Fig. 13. However, current distortions will be more when SRM is switched by soft chopping and hard chopping when compare to single pulse operation In soft chopping, one of the switches remains on and therefore the ripple content is less. In hard chopping, both the switches are on and off, therefore the ripple is high with power factor controller. Though current is distorted, it is nearly sinusoidal and the power factor is also almost unity. These results are shown in Fig. 14 and 15. In both soft chopping as well as hard chopping, the current increases in regular steps with constant average slope due to the switching of the machine converter and inductance profile. 

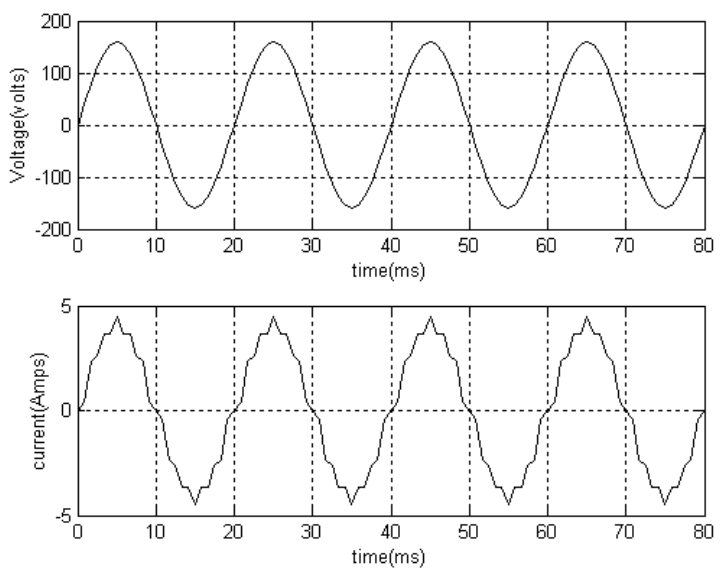

Fig. 14: Input voltage and current waveforms with power factor correction circuit at soft chopping
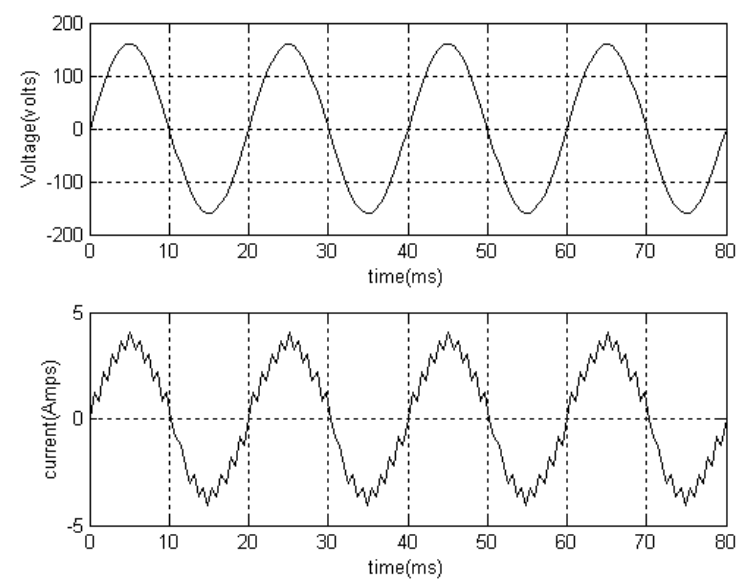

Fig. 15: Input voltage and current waveforms with power factor correction circuit at hard chopping
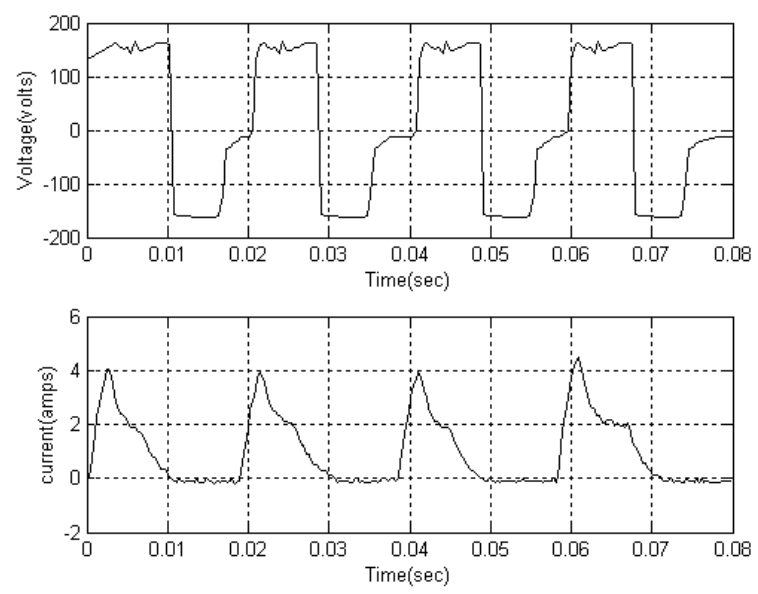

Fig. 16: SR Motor phase voltage and phase current waveforms at single pulse operation
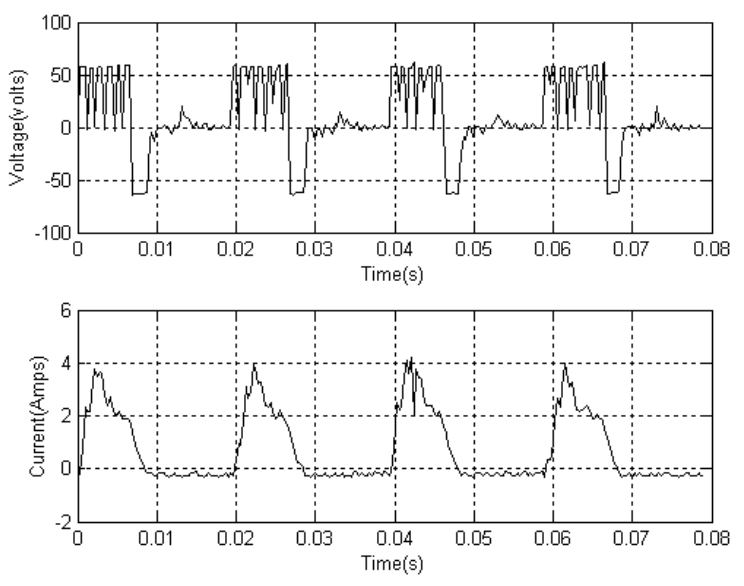

Fig. 17: SR Motor phase voltage and phase current waveforms at single pulse operation
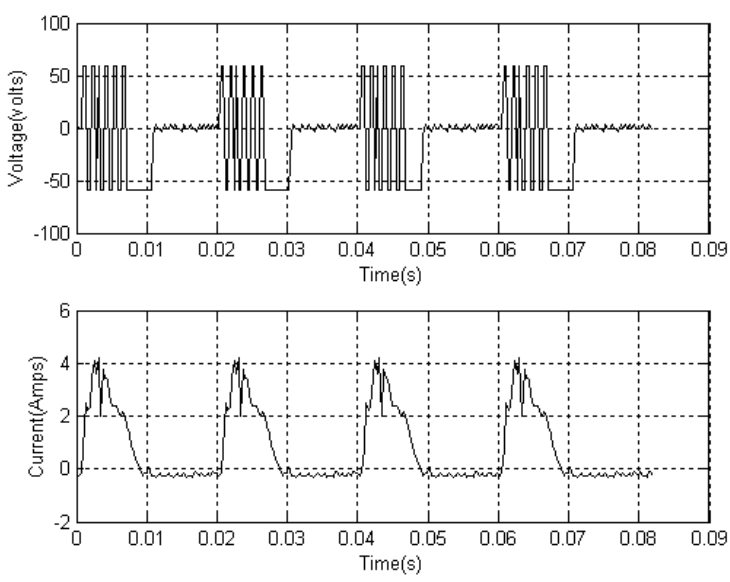

Fig. 18: SR Motor phase voltage and phase current waveforms at hard chopping operation

The single pulse, soft chopping and hard chopping operations the SR motor phase voltage and phase current waveforms during the normal operations are shown in the Fig. 16-18. The current in a particular phase starts increasing when the chopping mode starts and it starts decreasing when the chopping stops. In all the results obtained for a full rotation of a switched reluctance motor, in each cycle, the results obtained are similar in nature.

From the analysis it is understood that, the current waveform of the circuit is improved and the harmonics of the current is reduced to a great extend. Thus the power factor of the circuit is improved by employing the buck boost converter circuit for the different operating modes.

\section{CONCLUSION}

In this study, a novel SRM drive system with power factor correction circuit was proposed and results 
were discussed. From the results, it is observed that the proposed scheme achieves near sinusoidal current and almost unity power factor with high non-linear load like SRM The proposed power factor correction circuit was simulated with SRM in different operating modes such as single pulse, soft chopping and hard chopping.

\section{REFERENCES}

1. Miller, T.J.E., 1993. Switched Reluctance Motors and Their Control. Oxford Univ. Press.

2. Lawrenson, P.J., P.T. Blenkinsop, J. Corda and N.N. Fu1ton, 1980. Variable-speed switched reluctance motors. Proc. IEE. Pt. E, w, 2S3-2B5.

3. Jurgen Reinert and Stefan Schroder, 2002. Powerfactor correction for switched reluctance drives. IEEE Trans. Indust. Electron., 49: 54-57.

4. Krishnan, R. and S. Lee, 1994. Effect of power factor correction circuit on switched reluctance motor drives for appliances. Ninth Ann. Appl. Power Electron. Conf. Exposition, APEC '94. 1: 83-89.
5. Caruso, L., A. Consoli, G. Scarcella and A. Testa, 1996. A switched reluctance motor drive operating at unity power factor. Indust. Applic. Conf. ThirtyFirst IAS Annual Meeting, IAS '96, 1: 410-417.

6. Corda, J. and M. Oljada, 1991. Harmonic analysis of current waveforms in the DC link of a switched reluctance drive. Fifth Intl. Conf. Electrical Machines and Drives, pp: 86-9.

7. Andersen, G.K., L. Helle and P.O. Rasmussen, 1999. An Integrated single phase power factor controlled swithed reluctance motor drive with minimum of passive components. EPE-1999.

8. Geun-Hie Rim, Won-Ho Kim, Eun-Soo Kim and Ki- Chul Lee, 1994. A choppingless converter for switched reluctance motor with unity power factor and sinusoidal input current. Power Electronics Specialists Conf., PESC '94 Record., 25th Annual IEEE pp: 500-507.

9. Krishnan. R., 2001. Switched Reluctance Motor Drives. CRC Press. 